Ensino, Saúde e Ambiente-V4 (3), pp.93-105, dez. 2011

\title{
USO DE RECURSOS ÁUDIO-VISUAIS EM SALA DE AULA PARA SENSIBILIZAÇÃO DA COMUNIDADE ESCOLAR CONTRA AS DROGAS PSICOTRÓPICAS
}

\section{USE OF AUDIO-VISUAL RESOURCES IN THE CLASSROOM TO THE COMMUNITY SCHOOL AWARENESS AGAINST PSYCHOTROPIC DRUGS}

\author{
Adriana Maria Antunes ${ }^{1}$, Vanessa Rafaela Milhomem Cruz ${ }^{2}$, \\ Joana Cristina Neves de Menezes Faria ${ }^{3}$ \\ ${ }^{1}$ Mestranda do programa de Pós-Graduação em Biologia, modalidade Biologia Celular e \\ Molecular, do Instituto de Ciências Biológicas, da Universidade Federal de Goiás. \\ adrianaantunesbio@gmail.com \\ ${ }^{2}$ Graduanda em Ciências Biológicas - Licenciatura da Universidade Federal de Goiás. \\ ${ }^{3}$ Mestre em Biologia pela Universidade Federal de Goiás.
}

\section{RESUMO}

O problema das drogas tem se tornado cada vez mais comum entre os adolescentes e jovens e por isso é necessário educar criticamente os escolares capacitando-os a tomar decisões conscientes e responsáveis. A presente pesquisa teve como objetivo verificar a eficácia do vídeo "Drogas: um caminho para o fim" como recurso tecnológico educacional capaz de sensibilizar a comunidade escolar contra o uso de drogas psicotrópicas. $\mathrm{O}$ vídeo foi exibido para 60 estudantes pertencentes ao $8^{\circ}$ ano do Ensino Fundamental, de uma escola pública de Goiânia-GO, e em seguida foi realizado um debate sobre o assunto, que valorizou a contextualização e a problematização. Os resultados da pesquisa, avaliados por meio de um questionário pós intervenção, permitiu verificar que o vídeo despertou o interesse dos estudantes para o tema, contribuiu para a construção de uma aprendizagem significativa e sensibilizou os educandos para o não uso de drogas.

Palavras-chaves: vídeos educativos, motivação, aprendizagem significativa.

\begin{abstract}
The drug problem has become increasingly common among teenagers and young and so it is critically necessary to educate the students enabling them to make informed decisions and responsible. This study aimed to verify the effectiveness of the video "Drugs: a path to the end" as a educational technology able to sensitize the school community against the use of psychotropic drugs. The video was shown to 60 students in the eighth grade of elementary school in a public school in Goiânia-GO and then there was a discussion on the subject that valued context and questioning. Search results assessed by a questionnaire after the intervention has shown that the video awakened the interest of students to the topic contributed to the construction of a meaningful learning sensitized the students to not use drugs.
\end{abstract}

Keywords: educational videos, motivation, meaningful learning. 


\section{INTRODUÇÃO}

O uso de drogas no ambiente e idade escolar tem trazido preocupações e isto interfere no bem estar social. Mediante fatos do contexto atual diversos setores, autoridades e profissionais, têm buscado alternativas para o combate das drogas, dentre eles se destacam os profissionais vinculados a área de saúde pública e os educadores. Os primeiros são responsáveis especificamente pelo tratamento dos usuários, enquanto os profissionais da educação possuem a responsabilidade de sensibilizar esse público para preveni-los das conseqüências provenientes das drogas.

Diversos estudos têm sido realizados em detrimento da crescente proliferação dos usuários de drogas. Para Baus et al. 2002,

Tanto estudos de comportamento de risco em geral quanto aqueles com enfoque no uso de drogas nessa idade mostraram a importância dos fatores sociodemográficos, como idade, sexo e classe social, e fatores psicossociais, como a influência dos amigos e as relações interpessoais dentro da família, para o desenvolvimento e o tratamento desse problema de saúde. No Brasil, a única pesquisa sistemática de abrangência nacional sobre uso de drogas na idade escolar e alguns fatores de risco é realizada pelo Centro Brasileiro de Informações sobre Drogas Psicotrópicas (Cebrid), há aproximadamente 15 anos

As drogas têm invadido o ambiente escolar, o que preocupa os órgãos de saúde e os educadores. Várias são as pesquisas realizadas à pedido do Ministério Público de Saúde que tem demonstrado que as drogas mais utilizadas pelos adolescentes são as drogas psicotrópicas (SOLDERA et al, 2004).

As drogas psicotrópicas são aquelas que interferem no funcionamento do Sistema Nervoso Central (SNC), atuando sobre o cérebro e modificando a maneira de ser, agir, pensar e o comportamento do indivíduo. As substâncias psicotrópicas são classificadas em depressoras, estimulantes e perturbadoras de acordo com a sua ação no SNC (CARLINI, 2001).

As drogas depressoras diminuem a atividade cerebral, deixando os estímulos nervosos mais lentos; fazem parte desse grupo o álcool, calmantes e sedativos, solventes e opiáceos. As drogas estimulantes aumentam a atividade cerebral e excitam principalmente as áreas sensoriais e motoras; são representadas pelo tabaco, cocaína, crack e as anfetaminas. A mais devastadora são as drogas pertubadoras que são capazes de fazer o cérebro funcionar fora do seu estado normal. Elas não alteram a velocidade dos estímulos cerebrais, mas causam perturbações na mente levando o individuo a ter conseqüências irreversíveis por toda a vida; são exemplos desse grupo a maconha, plantas alucinógenas, LSD, êxtase e os solventes orgânicos. A maioria das 
drogas psicotrópicas levam a dependência química, o quer as tornam ainda mais destruídoras ao usuário (CARLINI, 2001).

$\mathrm{O}$ aumento do uso de drogas pelos adolescentes e jovens estudantes gera grandes preocupações aos educadores. O CEBRID (Centro Brasileiro de Informações sobre Drogas Psicotrópicas) em 1987 realizou uma pesquisa entre os estudantes de $1^{\circ} \mathrm{e}$ $2^{\circ}$ graus residentes em dez capitais e constatou um consumo principalmente do álcool, tabaco e dos solventes (CARLINI et al, 1989). No entanto no ano de 1997 o mesmo estudo foi realizado e observou-se novamente o aumento do uso do álcool, tabaco e solvente, mas com um diferencial, constatou-se um aumento significativo quanto ao consumo de maconha, principalmente entre o gênero masculino, dados esses irrelevantes na pesquisa de dez anos atrás (GALDUROZ et al, 1997).

Silva et al (2006) realizou também o estudo com escolares em São José do Rio Preto, e constatou que o consumo de drogas ilícitas atinge níveis altíssimos para o uso de maconha na adolescência. Esses dados corroboram com Muza et al (1997), em que a taxa de prevalência do uso de substâncias lícitas e ilícitas crescem em progressão aritmética com a idade, principalmente na faixa etária dos 13 a 15 para a faixa dos 16 a 17 anos, sendo que a maconha apresenta altas taxas de prevalência entre os adolescentes.

Os adolescentes são os mais suscetíveis ao uso de drogas, no qual o consumo tem ocorrido em idades entre 10 e 12 anos (SANCHEZ et al, 2005). A adolescência é uma época de exposição e experimentação de substâncias lícitas (bebidas alcolicas e cigarro) e ilícitas (drogas psicoativas), e Tavares et al, 2004 considera que:

Para alguns adolescentes, o uso indevido de substâncias será apenas parte de seu processo de desenvolvimento, podendo cessar com seu amadurecimento. Outros, porém, desenvolverão um uso problemático, interrompendo o processo normal da adolescência, podendo trazer graves conseqüências para a vida desses indivíduos

Para Costa et al. (2007), em pesquisa realizada com mais de 1300 adolescentes das escolas públicas de Feira de Santana na Bahia sobre o uso de álcool, cigarros e drogas psicoativas mais de $62 \%$ dos estudantes referiram a escola como um veículo de informação sobre o uso de drogas, no qual as palestras e os diálogos entre os professores foram usados como proposta para a sensibilização da temática de drogas na escola. 
Dentre as pesquisas realizadas sobre as drogas merece destaque aquelas que avaliam as instituições de ensino. Moreira et al. (2006) teve como "objetivo revisar os modelos de prevenção do uso indevido de drogas em ambiente escolar, relacionando-os aos conceitos de "promoção de saúde" e " escola promotora de saúde", e a partir disso, propor um modelo de intervenção".

Diante dessa perspectiva, a escola deve propiciar aos educandos atividades diferenciadas para atender as expectativas e até mesmo as particularidades de grupos heterogêneos, além de preocupar-se com o posicionamento dos mesmos. As alternativas para socializar temáticas relacionadas a saúde no ambiente escolar pode variar conforme o perfil do professor. Os professores possuem papel fundamental na interação com seus alunos e os mesmos devem estar sempre inteirados dos temas da atualidade e até mesmo do contexto social do educando para obter maior resultado em suas intervenções.

Para isso, Rebello et al. (2001) descreve em sua pesquisa a realização de uma metodologia diferenciada por meio de um jogo educativo para trabalhar a temática: "consumo indevido de drogas" com a coleta de dados para representar a visão dos educandos participantes em relação ao assunto e prática pedagógica. Além disso, outras diferentes estratégias têm sido utilizadas no ambiente escolar, pois elas devem estar constantemente aliadas a prática do professor. Assim entende-se que: jogos, vídeos, animações, moldes, maquetes, palestras, entre outros, são alternativas a serem utilizados na sala de aula para maior interação dos educando para entendimento do tema vigente.

Os vídeos em especial são ferramentas pedagógicas que podem ser utilizadas para diferentes abordagens na escola. Segundo, Moran (2005) os vídeos educativos em instituições de ensino devem funcionar como meio de sensibilização:

É, do meu ponto de vista, o uso mais importante na escola. Um bom vídeo é interessantíssimo para introduzir um novo assunto, para despertar a curiosidade, a motivação para novos temas. Isso facilitará o desejo de pesquisa nos alunos para aprofundar o assunto do vídeo e da matéria (1995, p. 27-35).

O vídeo exercita os sentidos, atingindo a atenção dos expectadores por conter sons, imagens e movimentos, de forma que os estudantes podem visualizar as cenas em sua realidade e não apenas pela imaginação, o que garante a transmissão de informações e fatos reais (Moran, 2005). Ainda sobre os benefícios dessa metodologia Oliveira et al. (2010) afirma que " o vídeo se insere como ferramenta motivadora e não como instrumento que refaz uma aula teórica na televisão". 
As aulas teóricas na grande maioria são baseadas exclusivamente no uso do livro didático, porém há informações que não são esclarecidas apenas com a leitura. Dessa maneira, é bem provável que o educando não tenha o aprendizado concretizado, por isso nota-se a real necessidade de interferências na mediação do professor em sala de aula por meio de tecnologias educacionais como exemplo, os vídeos. Nesse sentido, o educando passa a ter outro olhar sobre a temática abordada e perceber a importância das informações com significado para sua vida.

Entender, refletir, assimilar e se interar são expressões que deve fazer parte dos objetivos do profissional da educação ao se preocupar com a elaboração de uma aula, principalmente quando se trata de assuntos polêmicos como as drogas. Saber o que são drogas, quais os tipos, quais os malefícios, qual a sensação após o uso, tudo isto, são informações do senso comum e que muitas das vezes os alunos falam ou até mesmo acham que já entendem. Porém esse assunto deve ser trabalhado com uma abordagem bastante instigadora e científica para promover maior reflexão desse público.

Este trabalho se identifica como uma das alternativas para combater o uso das drogas na comunidade escolar por meio de recursos áudio-visuais em sala de aula e sensibilizar principalmente os educandos.

\section{OBJETIVOS}

- Verificar a eficácia do vídeo como recurso tecnológico educacional;

- Abordar a temática "Drogas psicotrópicas" de forma motivadora;

- Informar a comunidade escolar acerca dos prejuízos que as drogas causam a saúde do usuário e sobre os problemas sociais gerados pelas drogas;

- Sensibilizar a comunidade escolar contra o uso de drogas psicotrópicas.

\section{METODOLOGIA}

\section{A) Público-alvo}

A presente pesquisa foi desenvolvida por professoras de Ciências/Biologia, em uma escola da rede pública de ensino, que preferiu ter a sua identidade ocultada, tendo como público alvo 60 estudantes pertencentes a duas turmas do $8^{\circ}$ ano do Ensino Fundamental, que possuíam faixa etária entre 13 e 15 anos e eram oriundos de diversos bairros da cidade de Goiânia. 


\section{B) Elaboração da proposta educacional}

Esta proposta pedagógica almeja associar o uso da tecnologia em sala de aula, por meio da exibição de vídeos, às atividades educacionais que tem o intuito de sensibilizar a comunidade escolar contra o uso de drogas psicotrópicas. Isto porque é crescente a necessidade de educar criticamente os adolescentes, fazendo-os refletir sobre a problemática das drogas e com isso capacitando-os a tomar decisões conscientes e responsáveis.

O vídeo exibido em sala de aula foi idealizado e construído pelas professoras de ciência após revisão da literatura com bases na temática "Drogas psicoativas" e na utilização de vídeos como metodologias de ensino, o que possibilitou as docentes adquirir um referencial teórico sobre este tema, e direcionou-as na construção do vídeo educativo. Nesse sentido o vídeo foi planejado com o objetivo de favorecer o processo de ensino-aprendizado.

\section{C) Apresentação dos recursos audiovisuais}

O vídeo intitulado "Drogas: um caminho para o fim"1 foi construído por meio do programa editor de vídeos Portable Windows Movie Maker 2.1.4026.0, instalado no sistema operacional Windows XP. Este vídeo possui cerca de cinco minutos de duração e aborda de forma critica e reflexiva conteúdos relacionados a drogas.

O presente recurso áudio-visual fala sobre a atuação das drogas psicoativas nas sinapses do sistema nervoso central, deprimindo, estimulando ou perturbando a atividade cerebral. O vídeo cita os motivos que podem levar as pessoas a começar a usar drogas, entre eles a necessidade de fuga dos problemas cotidianos, a curiosidade e a pressão dos "amigos". Além disso, ele problematiza acerca das verdadeiras amizades, dizendo que amigos de verdade não querem que você use drogas, muito pelo contrário, querem o melhor para você. O vídeo aborda a questão da dependência física e psíquica a droga e a dificuldade de abandono do vício. Ele relata alguns danos à saúde causados pelo uso de drogas e citam a violência e prostituição como problemas sociais que podem ser gerados pelas drogas. Por fim, o vídeo mostra que todos podem escolher um caminho para seguir, mas que o melhor caminho é aquele longe das drogas.

\footnotetext{
${ }^{1}$ http://www.youtube.com/watch?v=ngk6jlmtrCY
} 

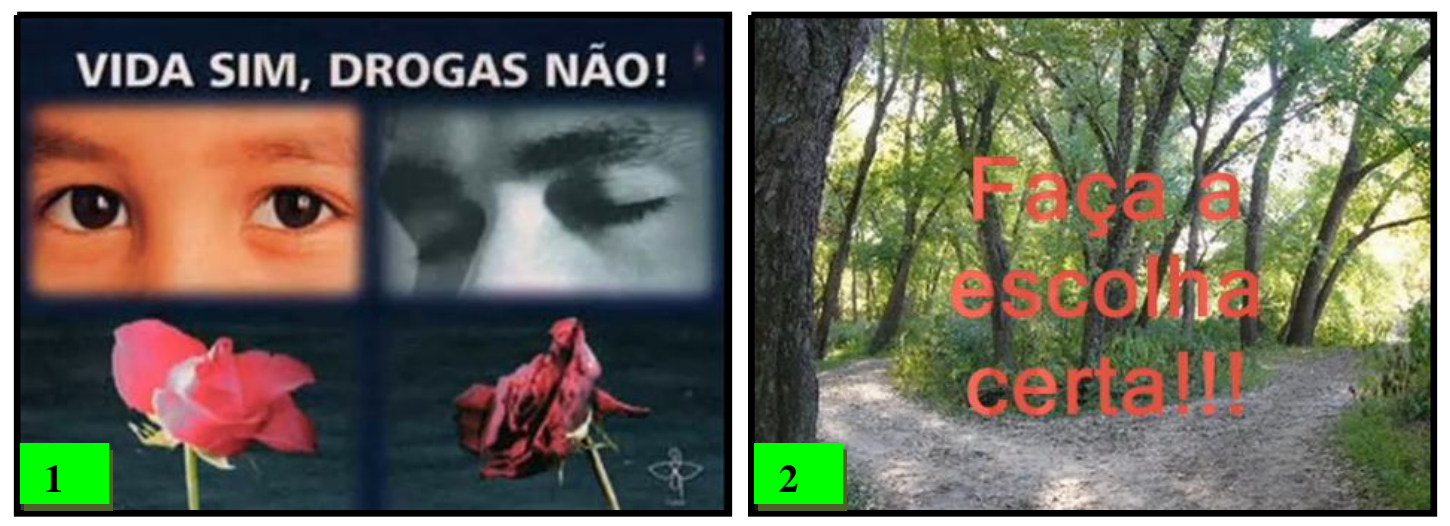

Figuras 1 e 2: Cenas retiradas dos vídeos “Drogas: um caminho para o fim”.

\section{D) Desenvolvimento das atividades educativas}

O vídeo foi exibido após uma aula introdutória acerca do conteúdo "Drogas psicoativas”. Durante essa aula inicial a professora discutiu com os estudantes o efeito das drogas no Sistema Nervoso Central, explicando a atuação das drogas estimulantes, depressoras e perturbadoras no cérebro. $\mathrm{O}$ vídeo foi apresentado às turmas como forma de dar continuidade ao conteúdo, possibilitando maiores discussões acerca dos prejuízos que as drogas podem causar a saúde dos usuários, bem como sobre problemas sociais provocados por ela.

Após a exibição do vídeo foi realizado um debate com o intuito de discutir conceitos básicos sobre a problemática gerada devido ao uso de drogas. Durante as discussões a professora teve a preocupação de problematizar a respeito dos assuntos, visando não levar idéias prontas aos estudantes, mas fazê-los refletir e chegar a suas próprias conclusões. Nesse sentido a problematização foi realizada de forma a desenvolver a capacidade crítica dos educandos. Além disso, a professora mediadora do debate deu relevância para a contextualização dos pontos levantados, visando mostrar aos estudantes que esse problema existe perto deles, e que é necessário atenção, conhecimento e responsabilidade para não se envolver com drogas.

\section{E) Avaliação}

A avaliação da proposta pedagógica realizada com o vídeo foi desempenhada de maneira qualitativa e quantitativa. A análise qualitativa foi feita através de observações in loco das expressões orais dos estudantes e registros escritos das discussões durante as atividades educacionais. 
A análise quantitativa foi realizada por meio de dados coletados por um questionário pós-intervenção, e avaliou o conhecimento adquirido ao longo das atividades educativas. Segundo Mattar (1996), o questionário corresponde a um conjunto de perguntas, que a pessoa lê e responde sem a presença de um entrevistador. Os questionários da presente pesquisa foram construídos com questões abertas, onde as pessoas respondem as perguntas com suas próprias palavras. As vantagens desse tipo de pergunta é que permite a coleta de uma grande quantidade de dados, no entanto são de difícil tabulação e análise e podem surgir dificuldades de entendimento como, por exemplo, letra ilegível, erro de redação, etc (MATTAR, 1996).

\section{RESULTADOS E DISCUSSÃO}

Os estudantes foram bastante receptivos à apresentação do vídeo "Drogas: um caminho para o fim”. Este recurso metodológico foi eficaz em sala de aula, uma vez que motivou os estudantes, despertando seu interesse para o conteúdo. Os alunos fizeram silêncio total durante a exibição do vídeo, e se mostraram atentos a cada cena, o que é totalmente incomum nestas salas de aula (Figuras 3 e 4). Estes resultados estão de acordo com Rosa (2000) que afirmam que atividades diferentes das desenvolvidas no cotidiado estimulam os alunos para as práticas educativas. Além disso, Moran (2005) afirma que o vídeo desperta a curiosidade e traz motivação para a abordagem de novos temas.
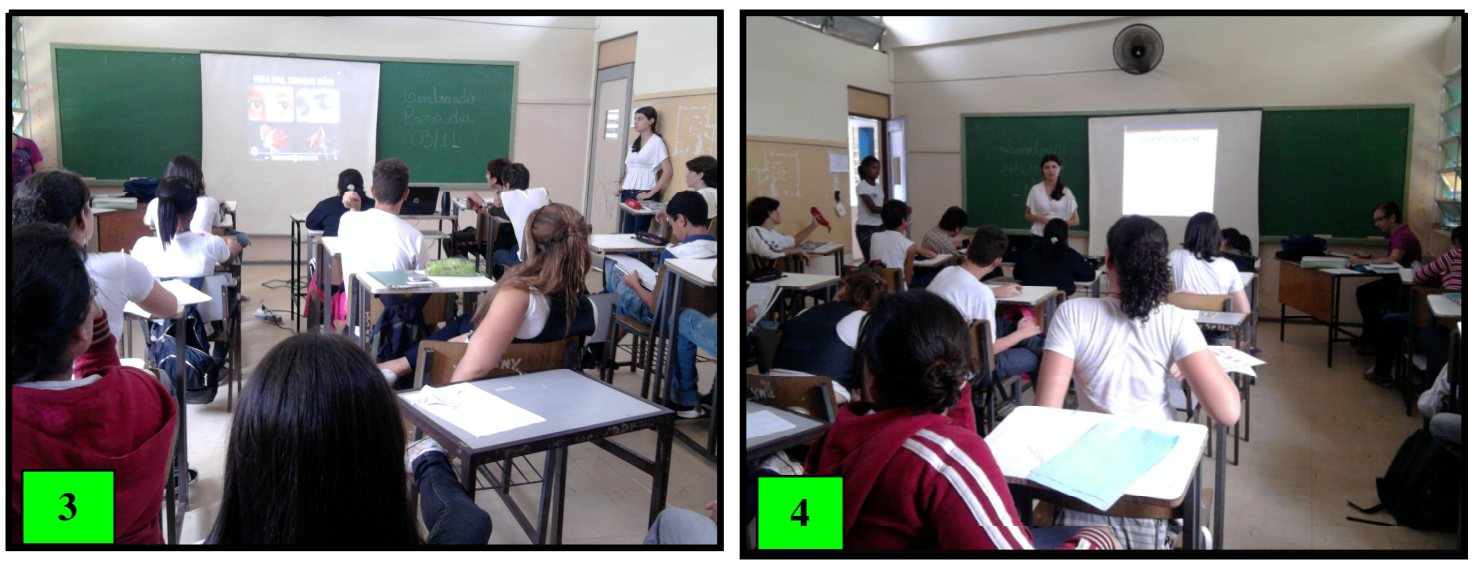

Figura 3 e 4 - Fotos da exibição do vídeo em uma das turmas do $8^{\circ}$ ano.

Durante o debate realizado após o vídeo os estudantes se envolveram significativamente nas discussões. No decorrer do debate os estudantes participaram expondo conhecimentos cotidianos, contando casos conhecidos por eles e fazendo 
perguntas sobre cada tipo de droga. A professora aproveitou estas colocações para contextualizar as discussões sobre drogas, o que é importante já que esta problemática pode estar próxima dos estudantes, podendo ate estar presente dentro da própria escola. A contextualização é valorizada por Antunes (2010), ao afirma que:

A contextualização no processo de ensino consegue prender de forma mais efetiva a atenção dos estudantes para o conteúdo abordado uma vez que ela permite a valorização do cotidiano, ou seja, os estudantes verificam uma relação intrínseca entre os saberes escolares e as questões concretas da vida, o que gera um significado para os conteúdos curriculares.

As discussões mediadas pela professora contemplou bastante o uso da problematização. Foram levantadas questões como: Como as drogas atuam no sistema nervoso? Porque as drogas geram violência? Porque devemos dizer NÃO ao uso de drogas? Perguntas como estas direcionaram as discussões e levaram os estudantes a refletir sobre o assunto. Segundo Freire (1987, p.70), a problematização favorece a participação ativa dos estudantes nas aulas e permite que eles pensem criticamente sobre o contexto, criticando, buscando a superação das dificuldades e transformando a própria realidade. A problematização contribui para a formação de pessoas pensante capazes de gerar mudanças significativas na sociedade.

No questionário respondido pelos estudantes após a exibição do vídeo e o debate, eles responderam se haviam gostado de assistir ao vídeo na aula de ciências e se gostariam de ter mais aula com esse recurso metodológico, e a cerca de $90 \%$ deles responderam que sim para as duas indagações, afirmando que:

\footnotetext{
"Com os vídeos aprendemos a matéria com mais facilidade”; E1

"O vídeo é muito interessante, então prestamos mais atenção”; $\mathbf{E 2}$

"Com o vídeo a aula fica mais legal e a gente aprende mais"; E3

"Achei legal esse vídeo porque deixamos de lado aquela aula em que a professora fala e fala e não aprendemos nada. Com o vídeo eu li o conteúdo nas legendas e eu aprendo mais lendo do que ouvindo"; $\mathbf{E 4}$

"O vídeo é legal porque a professora não precisa ficar gritando e pode voltar quantas vezes quiser”. E5
}

Foi possível constatar com a avaliação do questionário que os estudantes aprenderam significativamente o conteúdo referente a drogas, visto que ao analisar as respostas elaboradas por eles para as três questões teoricas iniciais "1-O que são drogas psicotrópicas?", “2-Quais as conseqüências do uso de drogas para o nosso organismo?", e "3-Cite e explique alguns problemas sociais provocados pelo uso de drogas.", verificamos que a maioria dos estudantes responderam estas questões corretamente, escrevendo respostas coerentes. Os dados quantitativos da análise de cada uma destas questões podem ser verificados no gráfico 1 . 


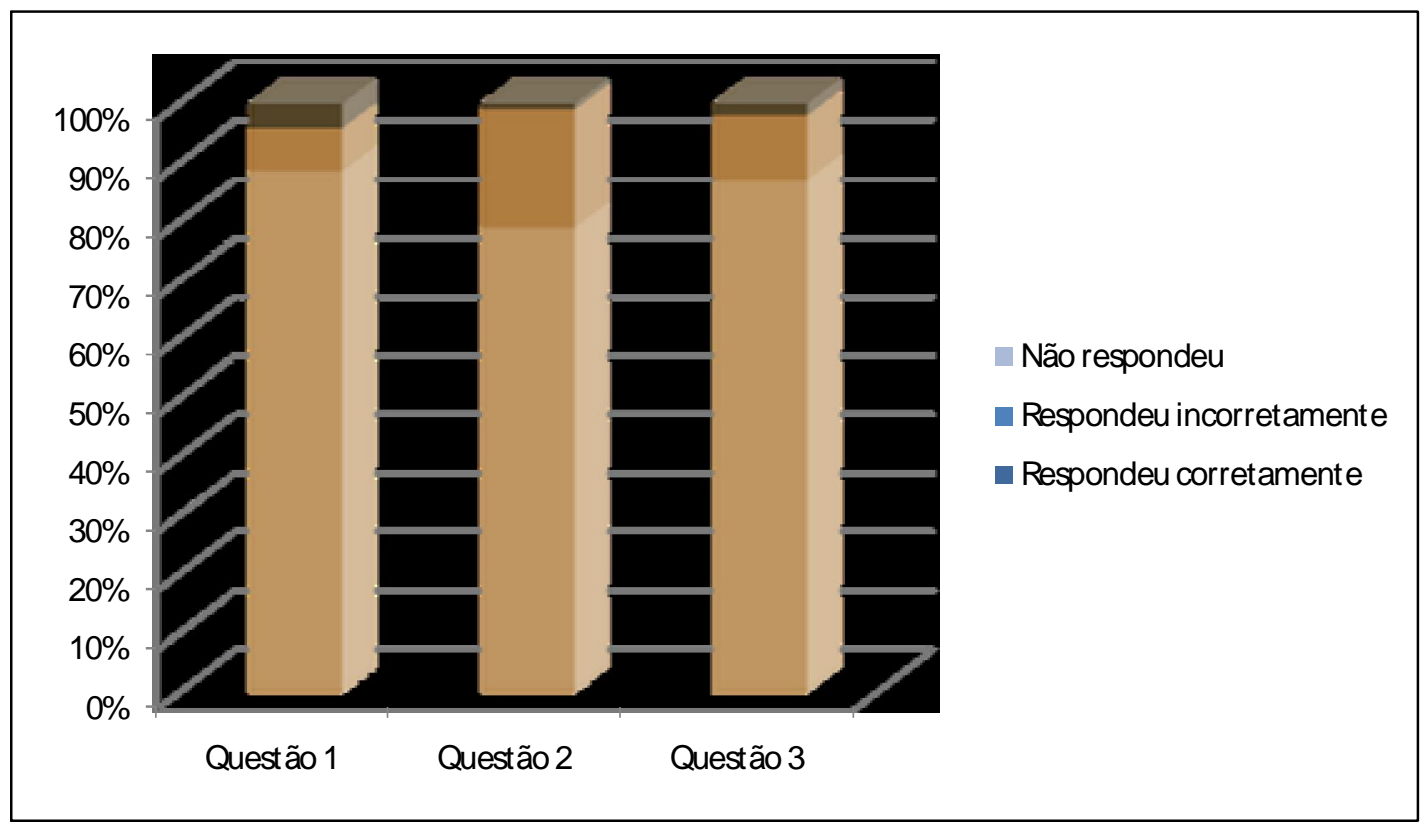

Gráfico 1 - Percentual de acertos dos estudantes as três questões iniciais do questionário.

Os dados apresentados no gráfico 1 podem ser justificados por Antunes (2010) ao afirmar que o uso de vídeos nas atividades educacionais constitui um recurso didático de grande valor, uma vez que contribui para um metódo de aula menos cansativo e para um aprendizado prazeroso, favorecendo assim uma aprendizagem significativa dos conteúdos escolares.

No questionário indagamos aos aprendentes se eles já tinham conhecimentos acerca da problemática das drogas e se eles consideram que o vídeo conseguiu alertá-los para esta questão. Todos os estudantes consideraram que o vídeo alertou para a problemática das drogas, estimulando a reflexão sobre esta questão, mesmo os $63 \%$ dos estudantes que disseram já possuir conhecimentos prévios sobre o assunto. Nesse sentido alguns aprendizes afirmaram que:

"O vídeo me alertou, mas minha mãe também conversa bastante sobre isso"; E6

"Eu já sabia um pouco sobre drogas porque o filho da amiga da minha mãe já foi usuário”; $\mathbf{E 7}$

"Eu já sabia dos problemas das drogas, tanto que já me ofereceram e eu recusei porque sabia dos riscos"; E8

"Eu sabia um pouco sobre esse assunto, mas agora vi que as drogas são mais perigosas do que eu já sabia”; E9

"Já tinha visto um pouco sobre isso na TV, mas o vídeo me alertou muito para as conseqüências do uso de drogas”. E10 
Dessa forma é possível ressaltar que a exibição do vídeo educativo permitiu aos estudantes confrontar um conhecimento novo com conhecimentos que já possuiam, ou seja, com conhecimentos prévios. De acorco com Carvalho (1996) a relação estabelecida entre conhecimento prévio e novo leva a aprendizagem significativa, visto que ao assimilar conhecimentos novos o educando pode reconstruir conhecimentos prévios. Nesse sentido, infere-se que no presente estudo mesmo os estudantes que já possuiam um saber cotidiano sobre drogas, construíram um novo conhecimento sobre o assunto baseado no saber cientifico, reconstruindo assim conceitos errôneos.

Neste sentido, durante as discussões realizadas após a exibição do vídeo a professora teve o intuito não só de construir com os estudantes os conhecimentos relacionados ao efeito das drogas no corpo humano e as conseqüências do uso delas para a saúde, como também de discutir problemas sociais relacionados ao vício e de forma reflexiva despertar nos estudantes a consciência da importância de dizer não as drogas. As expressões orais dos estudantes após a exibição do vídeo e as respostas dos mesmos ao questionário, permitiu concluir que o objetivo de sensibilizar para o não uso de drogas foi alcançado.

\section{CONSIDERAÇÕES FINAIS}

Após a exposição do vídeo "Drogas: um caminho para o fim" notou-se que esta tecnologia educacional foi eficaz em sala de aula uma vez que proporcionou grandes benefícios na prática pedagógica como um recurso de maior atração e motivação para o processo educativo. Foi possível perceber durante toda a metodologia desenvolvida que os educandos tiveram momentos reflexivos acerca do assunto abordado. Identificou-se por meio dos registros e falas dos estudantes um maior compromisso e clareza das informações no combate ás drogas. Os estudantes ao participar das discussões mostraram-se ativos em seu desenvolvimento cognitivo e no processo de ensinoaprendizagem e foram sensibilizados quanto aos perigos que é o uso de drogas psicotrópicas. 


\section{REFERÊNCIAS BIBLIOGRÁFICAS}

ANTUNES, A.M.; OLIVEIRA, M.L.; DUTRA,M.F.; Educação ambiental e novas tecnologias: o uso de vídeos em sala de aula para sensibilização da comunidade escolar. Enciclopedia Biosfera, v.6, N.10, 2010.

ANTUNES, A.M; SABÓIA-MORAIS,S.M.T. O jogo educação e saúde: uma proposta de mediação pedagógica no ensino de ciências. Experiências em Ensino de Ciências, V.5(2), p. 55-70, 2010.

BAUS, J; KUPEK, E; PIRES, M. Prevalência e fatores de risco relacionados ao uso de drogas entre escolares. Rev. Saúde Pública v.36(1), p.40-6, 2002.

CARLINI, E.A., CARLINI-COTRIN, B.H.; SILVA-FILHO, A.R.; BARBOSA, M.T.S.; II Levantamento nacional sobre uso de psicotrópicos em estudantes do 10 e 20 graus.

São Paulo: Centro Brasileiro de Informações Sobre Drogas Psicotrópicas, Departamento de Psicobiologia, Escola Paulista de Medicina, Universidade Federal de São Paulo; 1989.

CARLINI, E.A.; NAPPO, S.A.; GALDURÓZ, J.C.F.; NOTO,A.R. Drogas psicotrópicas - O que são e como agem. Revista IMESC, n³, p9-35, 2001.

COSTA, M.C.; ALVES, M.V.Q.M.; SANTOS, C.A.S.T.; CARVALHO, R.C.; SOUZA, K.E.P.; SOUZA, H.L. Experimentação e uso regular de bebidas alcoólicas, cigarros e outras substâncias psicoativas/SPA na adolescência. Ciência \& Saúde Coletiva, v.12(5), p.1143-1154, 2007.

FREIRE, P. Pedagogia do Oprimido. 17ª ed. Rio de Janeiro. Paz e Terra, 1987.

GALDURÓZ, J.C.F.; NOTO, A.R.;, CARLINI, E. IV Levantamento sobre o uso de drogas entre estudantes do 1 o e 2o graus em 10 capitais brasileiras. São Paulo: Centro Brasileiro de Informações Sobre Drogas Psicotrópicas, Departamento de Psicobiologia, Escola Paulista de Medicina, Universidade Federal de São Paulo; 1997.

MATTAR, F. N. Pesquisa de marketing: edição compacta. São Paulo: Atlas, 1996.

MORAN, J.M. Desafios da Televisão e do vídeo à Escola. In: Integração das tecnologias da Educação. Secretaria de Educação à Distância. Brasília: Ministério da Educação, Seed, 2005.

MOREIRA, F.G; SILVEIRA, D. X; ANDREOLI, S.B. Redução de danos do uso indevido de drogas no contexto da escola promotora de saúde. Ciência \& Saúde Coletiva, v.11(3), p.807-816, 2006.

MUZA, G.M.; BETTIOL, H.; MUCCILO, G.; BARBIERI, M. Consumo de substâncias psicoativas por adolescentes escolares de Ribeirão Preto, SP (Brasil)- Prevalência do consumo por sexo, idade e tipo de substâncias. Rev. Saúde Pública, v.31(1),p. 21-9, 1997. 
OLIVEIRA, M.L; CORREIA, R.S; GENOVESE, C.L.C.R. Conhecer para preservar: o documentário como projeto de intervenção escolar. Enciclopédia Biosfera, Centro

Científico Conhecer - Goiânia, v.6, N.9, 2010.

REBELLO, S; MONTEIRO, S; VARGAS, E.P. A visão de escolares sobre drogas no uso de um jogo educativo. Interface - Comunic, Saúde, Educ, v.5, N.8, p.75-88, 2001.

ROSA, P. R. S. O uso dos recursos audiovisuais e o ensino de ciências.

Cad.Cat.Ens.Fís., v.17,N.1, p.33-49, 2000.

SANCHEZ, Z.V.M.; OLIVEIRA, L.G.; NAPPO, S.A. Razões para o não-uso de drogas ilícitas entre jovens em situação de risco. Rev. Saúde Pública, v.39(4), p.599-605, 2005.

SILVA, E.F.; PAVANI, R.A.B.; MORAES, H.S.; NETO, F.C. Prevalência do uso de drogas entre escolares do ensino médio do Município de São José do Rio Preto, São Paulo, Brasil. Cad. Saúde Pública v.22(6), p.151-1158, 2006.

SOLDERA, M.; DALGALARRONDO, P.; FILHO, H.R.C.; SILVA, C.A.M. Uso de drogas psicotrópicas por estudantes: Prevalência e fatores sociais associados. Rev. Saúde Pública v.38(2), p.277-83, 2004.

TAVARES, B.F.; BÉRIA, J.U.; LIMA, M.S. Fatores associados ao uso de drogas entre adolescentes escolares. Rev. Saúde Pública, v.38(6), p.787-96, 2004. 